\title{
Epidemiological characteristics and burden of childhood and adolescent injuries: a survey of elementary and secondary students in Xiamen, China
}

Ya Fang ${ }^{1,2^{*}}$, Xiang Zhang ${ }^{3}$, Wei Chen ${ }^{1}$, Fang Lin ${ }^{1}$, Manqiong Yuan ${ }^{1,2}$, Zhi Geng ${ }^{1}$, Hong Y Y ${ }^{4}$ and Long Dai ${ }^{5}$

\begin{abstract}
Background: Injuries pose a considerable threat to the health of children and adolescents, and childhood injuries cause substantial economic loss for families and society. Many injuries are preventable. To provide a theoretical basis and empirical support for injury prevention interventions, we studied the epidemiological characteristics, risk factors, and burden of injuries among elementary and secondary school students in Xiamen, China.

Methods: Participants were enrolled through multi-stage stratified cluster random sampling of elementary and secondary students in Xiamen in 2010. Questionnaires were completed by students' parents or guardians to assay students' basic information, family background, occurrence of injuries in the past year, and burden of injuries. Chi-square tests and logistic regression were performed to identify the key factors of injuries.

Results: A total of 2,816 usable questionnaires reported 365 injury incidents in 303 students over 1 year. The incidence of injuries was $10.8 \%$. Students who were male, extroverted, suburban, had sibling(s), studied in grades 4-9, or whose parents were divorced or separated were more likely to suffer from injuries. Most injuries occurred during the summer months (from June to August), and in the afternoon. The main affected body parts were limbs, fingers or toes. Unintentional falls, collisions/strikes, sprains, and cuts/sharp instrument injuries were the predominant causes of injury. The overall economic burden of the 365 injury incidents was 1,014,649.1 RMB (148,666.5 USD) total, 3,348.7 RMB (490.65 USD) per capita, and 2,779.9 RMB (407.31 USD) per incident.

Conclusion: The injury incidence among elementary and secondary students in Xiamen, China is lower than Guangdong and Zhejiang but higher than Beijing and Shanghai. Injuries caused substantial economic and family burdens and threatened students' health and life. Childhood and adolescent injuries have become a serious public health problem that requires the urgent attention of the government, society, schools, and families. Injury control and prevention among elementary and secondary school students is essential and will help in multiple ways to reduce the burden on the family to build a harmonious family and society.
\end{abstract}

Keywords: Injury, Elementary and secondary students, Epidemiology, Burden

\footnotetext{
* Correspondence: fangya@xmu.edu.cn

${ }^{1}$ Key Laboratory of Health Technology Assessment in Fujian Province

University, School of Public Health, Xiamen University, Xiamen, China

${ }^{2}$ State Key Laboratory of Molecular Vaccinology and Molecular Diagnostics,

School of Public Health, Xiamen University, Xiamen, China

Full list of author information is available at the end of the article
} 


\section{Background}

Some injuries require urgent attention and are the leading cause of death for children and adolescents throughout the world [1-5]. According to data published by the World Health Organization (WHO) Global Burden of Disease, millions of children are affected by unintentional injuries annually and more than 2,000 children died from injuries daily in 2004 [2]. Tens of millions of children receive hospital treatment for non-fatal injuries yearly. Moreover, the burden of injury on children is socioeconomically unequal. More than $95 \%$ of all injurycaused deaths in children occurred in low-income and middle-income countries [1]. In China, a developing country, injury has replaced diseases as the leading cause of death among elementary and secondary school students since the 1990s [6,7]. In particular, as road transport infrastructure developed, the incidence of road traffic injuries grew unexpectedly rapidly [8].

Injuries are a considerable threat to the health of children and adolescents and cause substantial economic loss for families and society [9]. The number of deaths of children from unintentional injuries is staggering. In the United States, more than 9,000 children die from unintentional injuries each year-about 25 deaths per day [10]. Non-fatal injuries may cause lifelong disability or chronic pain that limits the performance of daily activities. About 9 million children are treated for injuries in emergency departments yearly and more than 225,000 require hospitalization, incurring costs of around 87 billion USD in medical and societal expenses related to childhood injuries [5]. Additionally, the psychological burden caused by a family's loss of a child is immeasurable.

Considerable evidence demonstrates that effective interventions can prevent the majority of childhood injuries. For example, setting minimum drinking age laws, lowering the blood alcohol concentration limit for drivers and reducing driving speeds around schools can effectively reduce childhood road traffic injuries $[1,11]$. A recent systematic review [12] indicated that prevention programs caused a significant reduction in adolescent injuries (relative risk $(R R)=0.62,95 \%$ confidence interval $(C I)[0.48$, $0.81]$ ), especially in girls. Both pre-season and in-season interventions were beneficial in reducing adolescent injuries. Another study showed that the average incidence of injury among secondary students reduced from $5.19 \%$ to $1.91 \%$ after a 5 -month education and training program in Guangdong, China [13].

Because of the substantial epidemiological and economic burden of childhood injuries and because injuries are preventable, a study on the epidemiological characteristics and risk factors of childhood injury was necessary. While there were previous studies on this topic in China focusing on specific regions and populations, research on childhood and adolescent injuries in Xiamen,
China had just begun and no relevant data sets were established. To provide a theoretical basis and empirical support for interventions, we aimed to (1) establish the prevalence and the major causes of injuries among elementary and secondary students in Xiamen, China; (2) identify the key indicators related to disparities in childhood and adolescent injuries; and (3) measure the economic and family burden of childhood and adolescent injuries. To accomplish these, we conducted an epidemiological study to understand the socio-demographic characteristics, risk factors and burden of injuries among elementary and secondary students in Xiamen, China.

\section{Methods \\ Definition of injuries}

In our study, we considered 14 types of injuries: traffic and road injuries, unintentional falls, collisions and strikes, sprains, cuts and sharp instrument injuries, crush injuries, drowning, suffocation, electrocution, burns and scalds, explosions, poisonings, animal attacks, and medical complications. Injury was defined following Wang SY (1998) [14] because the definition is suitable for China's national condition and most commonly used in studies of injuries in China. An event is considered as injury if any of the following three events occurred: (a) being treated and diagnosed with injuries at a hospital; (b) receiving emergency treatment or care from family, teachers, or classmates; or (c) being absent from class for more than half a day because of injury.

\section{Sampling strategy}

Subjects in our study were students in elementary (grades 1-6) and secondary (grades 7-12) schools in Xiamen, China. Multi-stage stratified cluster random sampling was performed to recruit students in 2010. Recruiting was performed by district. Xiamen is one of five special economic zones in China, and it has six districts: Huli, Siming, Haicang, Jimei, Xiang'an and Tong'an. According to economic conditions, the first two districts are classified as urban, the middle two districts as suburban, and the last two districts as exurban. At the first sampling stage, one urban, suburban, and exurban district was randomly selected. At the second stage, two elementary schools and two secondary schools were randomly selected from each selected district. At the third and last stage, we randomly chose one class from each grade in each school. Randomization was performed using simple random sampling in SPSS 17.0. All of the students in the sampled classes were enrolled in our study. Participants received a paper questionnaire and were asked to bring it home for their parents or guardians to answer the questions. 


\section{Measures}

The content of the questionnaire included the following. (1) Students' basic information: sex, age, height, weight, health status (good, fair, poor), personality (introversive, intermediate, extroversive), and number of siblings. (2) Students' family background: parents' age, education, occupations, marital status (married, divorced, separated, widowed), and incomes. (3) Occurrence of injuries in the past year: number of injuries, time and location of injury, injury type, events, and affected part of the body. (4) Burden of injuries: economic and family-related.

The economic burden of injuries was measured by direct economic burden, including medical and other expenses directly related to treatments for injuries; indirect economic burden, which refers specifically to family income loss due to parents' or families' absence at work caused by the children's injuries; and intangible economic burden, measured by the amount of money the family is willing to pay to avoid injuries. The family's burden of injuries was measured using the Family Burden Scale of Diseases (FBS) [15], which includes six dimensions: financial burden (FM1), disruption of family routine activities (FM2), disruption of family leisure (FM3), disruption of family interaction (FM4), effect on physical health (FM5), and effect on mental health (FM6). Each dimension contains two to six items, and each item has three responses: no impact, moderate impact and serious impact, scoring 0,1 and 2, respectively.

\section{Ethics statement}

Informed consent was acquired on the first page of the questionnaire. All respondents participated voluntarily and provided informed consent. This study was approved by the ethical review committee of the School of Public Health, Xiamen University.

\section{Data analysis}

A chi-square test was used to analyze the association between the incidence of injury and impact factors. A multivariate logistic regression model was used to analyze significant variables from the chi-square test. Cronbach's $\alpha$ coefficient was used to measure the internal consistency and reliability of the FBS. The six FBS dimensions were assessed as follows: (1) calculate the dimension scores by averaging the item scores within each dimension for each student; and (2) obtain the thresholds for each dimension by averaging all the students' dimension scores. There was considered to be no impact if the dimension score for an individual student is 0 , moderate impact if larger than 0 but less than the threshold, and serious impact at or above the threshold. We summarize the distributions of each dimension by reporting the frequency and relative frequency of each response. All statistical analyses were conducted using
SPSS 17.0. Data was double-entered and validated by two trained research assistants using Epidata 3.1.

\section{Results}

\section{Sampling characteristics}

A total of 2,960 questionnaires were issued and 2,918 finished questionnaires were received. The response rate was $98.6 \%$. Of the finished questionnaires, 2,816 (96.5\%) were complete therefore usable. Table 1 summarizes the demographic characteristics of the 2,816 students, their incidence of injuries, and the results of chi-square tests. In total, 303 students suffered from 365 injuries within the year, giving a $10.8 \%$ incidence of injuries. Boys were more likely to suffer injuries than girls. Students who were in grades 4-9, were living in suburban or exurban environments, were extroversive, had sibling(s), were of poor health status, were living with more than 7 people, or had a household income greater than 4,000 RMB/ month had a higher risk of injuries. Students whose parent(s) were low-educated (primary educated or below), performed manual labor, or were unmarried (divorced, separated or widowed) were more likely to suffer from injuries. Notably, the incidence of injuries was higher among extroversive students than introversive ones. Of the 303 injured students, most (84.2\%) were injured once, were non-introversive $(94.4 \%)$, and were not overweight $(86.9 \%)$; more than half were boys $(58.7 \%)$, more than half were in grades 4-9 (58.4\%), nearly three quarters $(74.3 \%)$ lived in suburban or exurban environments, half $(50.8 \%)$ were from a one-child family, and $60 \%$ had a household income of less than 4,000 RMB/month.

The characteristics of injury events are shown in Table 2. Here we group the months into four seasons because of seasonal variation in outdoor and indoor activities. We used morning, afternoon and evening as the three conventional time periods of the day. Of the 365 injuries, most (97.0\%) were unintentional, more than one third occurred during the summer (June to August) (36.4\%) and in school (35.1\%), and more than half happened in the afternoon (55.3\%) and affected the limbs (53.2\%). The main causes of injury were unintentional falls $(30.7 \%)$, collisions or strikes $(18.8 \%)$, sprains $(17.3 \%)$, and cuts or sharp instrument injuries (10.1\%).

\section{Statistical analysis of injury impact factors}

As Table 1 indicates, the significant impact factors for the incidence of injuries include sex, grade, residence, personality, number of siblings, health status, number of people living together, parents' educational level, parents' occupation, and parents' marital status. Treating these impact factors as covariates, multivariate stepwise logistic regression was performed, and the results are presented in Table 3. The variables of parents' education and parents' occupation did not enter the model. Among 
Table 1 Demographic characteristics and chi-square test results for 2,816 participant students

\begin{tabular}{|c|c|c|c|c|c|}
\hline Characteristic & All students & Injured students (times) & Incidence (times) (\%) & $x^{2}$ & $P$ \\
\hline Sex & & & & 12.702 & $<0.001$ \\
\hline Boys & 1382 & $178(216)$ & $12.9(15.6)$ & & \\
\hline Girls & 1434 & $125(149)$ & $8.7(10.4)$ & & \\
\hline Grade & & & & 12.617 & 0.006 \\
\hline $1-3$ & 737 & $61(67)$ & $8.3(9.1)$ & & \\
\hline $4-6$ & 723 & $81(100)$ & $11.2(13.8)$ & & \\
\hline $7-9$ & 691 & $96(117)$ & $13.9(16.9)$ & & \\
\hline $10-12$ & 665 & $65(81)$ & $9.8(12.2)$ & & \\
\hline Residence & & & & 8.854 & 0.012 \\
\hline Urban & 939 & $78(90)$ & $8.3(9.6)$ & & \\
\hline Suburban & 918 & 109 (138) & $11.9(15.0)$ & & \\
\hline Exurban & 959 & $116(137)$ & $12.1(14.3)$ & & \\
\hline BMI & & & & 0.005 & 0.942 \\
\hline$<24$ & 2448 & $263(316)$ & $10.7(12.9)$ & & \\
\hline$\geq 24$ & 368 & $40(49)$ & 10.9 (13.3) & & \\
\hline Personality & & & & 14.314 & 0.001 \\
\hline Introversive & 282 & $17(18)$ & $6.0(6.4)$ & & \\
\hline Intermediate & 1543 & $154(153)$ & 10.0(9.9) & & \\
\hline Extroversive & 991 & $132(194)$ & 13.3(19.6) & & \\
\hline Number of sibling & & & & 7.011 & 0.008 \\
\hline 0 & 1631 & $154(182)$ & $9.4(11.2)$ & & \\
\hline$\geq 1$ & 1185 & 149(183) & $12.6(15.4)$ & & \\
\hline Health Status & & & & 13.453 & 0.001 \\
\hline Good & 2144 & $211(253)$ & $9.8(11.8)$ & & \\
\hline Fair & 637 & $83(100)$ & $13.0(15.7)$ & & \\
\hline Poor & 35 & $17(12)$ & $25.7(34.3)$ & & \\
\hline Number of people living together & & & & 9.772 & 0.008 \\
\hline$\leq 3$ & 1142 & 117(143) & $10.2(12.5)$ & & \\
\hline $4-6$ & 1613 & 172(204) & 10.7(12.6) & & \\
\hline$\geq 7$ & 61 & 14(18) & $23.0(29.5)$ & & \\
\hline Father's educational level & & & & 6.110 & 0.047 \\
\hline$\leq$ grade 6 & 402 & $51(61)$ & $12.7(15.2)$ & & \\
\hline grade $7-12$ & 1563 & 179(219) & $11.5(14.0)$ & & \\
\hline$>$ grade 12 & 831 & $72(84)$ & $8.7(10.1)$ & & \\
\hline Missing & 20 & $1(1)$ & - & & \\
\hline Mather's educational level & & & & 8.404 & 0.015 \\
\hline$\leq$ grade 6 & 824 & 109(140) & 13.2(17.0) & & \\
\hline grade $7-12$ & 1402 & 144(153) & 10.3(10.9) & & \\
\hline$>$ grade 12 & 582 & $50(72)$ & 8.6(12.4) & & \\
\hline Missing & 8 & 0 & - & & \\
\hline Father's Occupation & & & & 10.839 & 0.028 \\
\hline Farmer & 175 & $16(21)$ & $9.1(12.0)$ & & \\
\hline Manual labor & 592 & $83(101)$ & $14.0(17.6)$ & & \\
\hline
\end{tabular}


Table 1 Demographic characteristics and chi-square test results for 2,816 participant students (Continued)

\begin{tabular}{|c|c|c|c|c|c|}
\hline White collar & 999 & $94(110)$ & $9.4(11.0)$ & & \\
\hline Individual merchant & 636 & $74(89)$ & $11.6(14.0)$ & & \\
\hline Others & 394 & $35(43)$ & $8.9(10.9)$ & & \\
\hline Missing & 20 & $1(1)$ & - & & \\
\hline Mother's Occupation & & & & 10.581 & 0.032 \\
\hline Farmer & 138 & $12(16)$ & $8.7(11.6)$ & & \\
\hline Manual labor & 561 & $76(87)$ & $13.5(15.5)$ & & \\
\hline White collar & 876 & $77(92)$ & $8.8(10.5)$ & & \\
\hline Individual merchant & 440 & $56(63)$ & $12.7(14.3)$ & & \\
\hline Others & 793 & $82(107)$ & 10.3(13.5) & & \\
\hline Missing & 8 & 0 & & & \\
\hline Parents' marital status & & & & 9.499 & 0.002 \\
\hline Married & 2697 & $280(341)$ & 10.4(12.6) & & \\
\hline Non-married & 119 & $23(24)$ & 19.3(20.2) & & \\
\hline Household income* & & & & 4.390 & 0.111 \\
\hline$<2000$ & 855 & $91(107)$ & $10.6(12.5)$ & & \\
\hline 2000-3999 & 920 & $91(106)$ & $9.9(11.5)$ & & \\
\hline$\geq 4000$ & 719 & $94(117)$ & $13.1(16.3)$ & & \\
\hline Missing & 322 & $27(35)$ & - & & \\
\hline Total & 2861 & $303(365)$ & $10.6(12.8)$ & & \\
\hline
\end{tabular}

${ }^{*} \mathrm{RMB} /$ month.

the entered variables, sex, grade, residence, health status, personality, number of siblings, and parents' marital status were statistically significant. The odds of injury were 1.8 times higher for boys than girls, 1.6 times higher for students living in exurban than in urban environments, 1.4 times higher for students in grades 4-9 than in grades 1-3, 2.9 times greater for extroversive students than introversive ones, 1.6 times greater for students with siblings than single children, and 2.8 times greater for students whose parents were of unmarried rather than married.

\section{Economic burden of injuries}

The direct economic burden of the 365 injuries among 303 students was 258,219.6 RMB (37,834.37 USD) total, 852.2 RMB (124.86 USD) per capita, and 707.5 RMB (103.66 USD) per incident. The outpatient expenses were 91,396.6 RMB (13,391.44 USD) (35.4\%) and the hospitalization expenses were 147,885 RMB (21,668.13 USD) (57.3\%). The expenses for travel, care, nutrition and rehabilitation supplies were 18,938 RMB (2,774.80 USD) (7.3\%). The indirect economic burden of the 365 injuries was $88,948 \mathrm{RMB}(13,032.67$ USD) total, 293.6 RMB (43.02 USD) per capita, and 243.7 RMB (35.71 USD) per incident. The intangible economic burden was 667,481.5 RMB (97,799.49 USD) total, 2,202.9 RMB (322.77 USD) per capita, and 1,828.7 RMB (267.94 USD) per incident. Altogether, the total economic burden (including the direct, indirect, and intangible economic burden) of the 365 injuries amounted to 1,014,649.1 RMB (148,666.5 USD) total, 3,348.7 RMB (490.65 USD) per capita, and 2,779.9 RMB (407.31 USD) per incident.

The economic burden of injuries with different characteristics is presented in Table 4. Although the incidence of injuries in students in grades 10-12 was lower, the direct and intangible economic burdens (1,146.3 RMB (167.96 USD) and 2,932.1 RMB (429.61 USD), respectively) associated with their injuries were higher. The indirect economic burden for students in grades 1-3 was higher (340.3 RMB (49.86 USD)). The total economic burden was higher (4,175.9 RMB (611.85 USD)) for students living in urban areas. Among the 14 causes of injury, the highest per capita economic burdens were caused by medical complications, poisoning, and traffic accidents.

Table 5 presents the frequencies and relative frequencies of different responses to the six dimensions of FMS. The positive response rates (moderate impact and serious impact) rates were: financial burden (FM1) (58.8\%), the disruption of family routine activities (FM2) (65\%), the disruption of family leisure (FM3) (58.4\%), and the disruption of family interaction (FM4) (46.2\%). For the FMS overall, the positive response rate was $74.9 \%$. The Cronbach $\alpha$ for the six dimensions (FM1-FM6) were 
Table 2 Characteristics of student injury incidents by proportion and percentage

\begin{tabular}{|c|c|c|}
\hline & Number of injury & Proportion (\%) \\
\hline \multicolumn{3}{|l|}{ Type of injury } \\
\hline Unintentional & 354 & 97.0 \\
\hline Intentional & 11 & 3.0 \\
\hline \multicolumn{3}{|l|}{ Month of injury } \\
\hline December to February & 58 & 15.9 \\
\hline March to May & 80 & 21.9 \\
\hline June to August & 133 & 36.4 \\
\hline September to November & 94 & 25.8 \\
\hline \multicolumn{3}{|l|}{ Time of day } \\
\hline Morning & 78 & 21.4 \\
\hline Afternoon & 202 & 55.3 \\
\hline Evening & 85 & 23.3 \\
\hline \multicolumn{3}{|l|}{ Location } \\
\hline School & 128 & 35.1 \\
\hline Home/Dormitory & 76 & 20.8 \\
\hline Road/Street & 63 & 17.3 \\
\hline Public places & 47 & 11.5 \\
\hline Sports venues outside school & 42 & 12.9 \\
\hline Other & 9 & 2.5 \\
\hline \multicolumn{3}{|l|}{ Part of body affected } \\
\hline Lower limb & 113 & 31.0 \\
\hline Upper limb & 81 & 22.2 \\
\hline Fingers/Toes & 67 & 18.4 \\
\hline Face & 37 & 10.1 \\
\hline Head and Neck & 30 & 8.2 \\
\hline Torso & 13 & 3.6 \\
\hline Multiple parts & 13 & 3.6 \\
\hline Organ & 11 & 3.0 \\
\hline Total & 365 & 100.0 \\
\hline
\end{tabular}

$0.889,0.912,0.907,0.926,0.902$, and 0.892 , respectively, and 0.961 for the FMS overall.

\section{Discussion}

Injury has become a public health problem that threatens elementary and secondary students' health and causes substantial economic burden. Our study shows that the incidence of injuries in elementary and secondary students in Xiamen, China was $10.8 \%$, lower than in Guangdong and Zhejiang provinces [16-20], but higher than in Beijing and Shanghai [21,22]. Extrapolating from data from the Xiamen Special Economic Zone Yearbook of 2013 [23], we estimate that 45,361 injuries have occurred annually among 37,685 elementary and secondary students in Xiamen, given that there were a total of 348,933 elementary and secondary students in Xiamen in 2012.
The incidence of injuries for the students living in suburban areas (12.0\%) was higher than those in urban areas (8.3\%). This may be because urban students had better living and learning environments and were well supervised and protected by their guardians. The incidence of injuries among boys (12.9\%) was higher than girls $(8.7 \%)$, which is consistent with other regional research results [16-22]. Boys were more exposed to risk factors because they were more likely to join in outdoor activities like sports, while girls were less likely to undergo injuries because they were relatively cautious and introversive.

In addition, students in grades 4-9 were more likely to suffer injuries than those in grades $1-3$ or $10-12$. One possibility is that the students in grades 4-9 were more playful but lacked the self-awareness of protection, while the younger students were closely supervised by both teachers and parents, and the older students were too busy with their courses and preparing for the college entrance examination to participate in outdoor activities. Furthermore, the senior students were less likely to get injured because they had better physical coordination and greater awareness of self-protection. However, when injuries occurred, the economic burden for older students was higher, which indicates that their injuries were more serious. Students whose parents' educational levels were lower had a higher risk of injuries. Parents have an integral role in their children's growth, and in general, more highly educated parents provide better education and supervision for their children to avoid injuries.

Almost all (97.0\%) injuries were unintentional. More than one third of the students' injuries occurred from June to August, likely because students engaged in outdoor activities more frequently in summer, with less protection from clothing and with more of their body exposed. In addition, more than half of the injuries occurred in the afternoon, the peak time for outdoor sports activities.

Most injuries of elementary and secondary school students occurred at school (35.1\%), at home or in dormitories $(20.8 \%)$, and on the road $(17.3 \%)$, which were the major places where students spent their time. In all areas and grades investigated, the school was where most injury occurred, so it is essential that schools provide a safe environment with high-quality education and living facilities to prevent and control student injuries. Arms/ legs and fingers/toes were the main affected body parts, which relates to the top three causes of injury: unintentional falls (30.7\%), collisions/strikes (18.8\%), and sprains (17.3\%).

Multivariate stepwise logistic regression analysis showed that the incidence of injuries varied significantly among areas, sexes and grades. The results suggest that injury prevention and control interventions should focus on 
Table 3 Results of multivariate stepwise logistic regression for injury impact factors

\begin{tabular}{|c|c|c|c|c|c|}
\hline Factors & $\beta$ & SE & Wald $X^{2}$ & $P$ & OR $(95 \% \mathrm{Cl})$ \\
\hline \multicolumn{6}{|l|}{ Sex } \\
\hline Girls & & & & & 1.000 \\
\hline Boys & 0.564 & 0.130 & 18.817 & 0.000 & $1.758(1.362-2.268)$ \\
\hline \multicolumn{6}{|l|}{ Grade } \\
\hline $1-3$ & & & & & 1.000 \\
\hline $4-6$ & 0.309 & 0.182 & 2.875 & 0.090 & $1.363(0.953-1.948)$ \\
\hline $7-9$ & 0.368 & 0.184 & 4.021 & 0.045 & $1.445(1.008-2.070)$ \\
\hline $10-12$ & -0.096 & 0.200 & 0.230 & 0.632 & $0.908(0.613-1.345)$ \\
\hline \multicolumn{6}{|l|}{ Residence } \\
\hline Urban & & & & & 1.000 \\
\hline Suburban & 0.385 & 0.161 & 5.741 & 0.017 & $1.470(1.073-2.014)$ \\
\hline Exurban & 0.486 & 0.159 & 9.312 & 0.002 & $1.626(1.190-2.221)$ \\
\hline \multicolumn{6}{|l|}{ Health Status } \\
\hline Good & & & & & 1.000 \\
\hline Fair & 0.394 & 0.145 & 7.388 & 0.007 & $1.483(1.116-1.971)$ \\
\hline Bad & 1.254 & 0.414 & 9.174 & 0.002 & $3.505(1.557-7.892)$ \\
\hline \multicolumn{6}{|l|}{ Personality } \\
\hline Introvert & & & & & 1.000 \\
\hline Middle & 0.676 & 0.269 & 6.296 & 0.012 & $1.966(1.159-3.334)$ \\
\hline Extrovert & 1.056 & 0.273 & 14.923 & 0.000 & $2.876(1.683-4.915)$ \\
\hline \multicolumn{6}{|c|}{ Number of siblings } \\
\hline$\geq 1$ & & & & & 1.000 \\
\hline 0 & 0.473 & 0.163 & 8.427 & 0.004 & $1.605(1.166-2.210)$ \\
\hline \multicolumn{6}{|c|}{ Parents' marriage } \\
\hline In marriage & & & & & 1.000 \\
\hline Non-married & 1.044 & 0.264 & 15.600 & 0.000 & $2.842(1.692-4.771)$ \\
\hline \multicolumn{6}{|c|}{ Number of people living together } \\
\hline$\leq 3$ & & & & & 1.000 \\
\hline $4-6$ & -0.166 & 0.159 & 1.083 & 0.298 & $0.847(0.620-1.158)$ \\
\hline$\geq 7$ & 0.734 & 0.343 & 4.568 & 0.033 & $2.083(1.063-4.082)$ \\
\hline
\end{tabular}

male elementary and secondary school students in suburban and exurban areas. Second, student injuries varied by health condition and personality. Students in fair or poor health were more likely to be affected by various levels and types of injuries. Extroversive students had more exposure to injury risk factors because they were more physically active. Therefore, we suggest that the primary aim of injury prevention and control interventions be to strengthen students' physique, cultivate their safety awareness, and improve their self-protection abilities. Third, students' injuries might be caused by their domestic situation. A child with sibling(s) may receive less concern and care from parents compared with a single child. Consequently, a child with sibling(s) is more likely to be ignored, and their risk of injury is accordingly higher. The odds of injury were higher in single-parent families. In addition, more people living together increased the chances of friction between students and others, thereby increasing the risk of injuries.

As our study indicated, the direct economic burden of student injury was 258,219.6 RMB (37,834.37 USD) in total, 852.2 RMB (124.86 USD) per capita and 707.5 RMB (103.66 USD) per incident from 365 injury incidents in 303 elementary and secondary school students in Xiamen in one year. This economic burden was higher than in Haidian District and Pinggu District in Beijing [21]. This might be because the Beijing survey was conducted earlier and the inflation rate was relatively high in recent years. In addition, injuries caused a total indirect economic burden of 88,948 RMB (13,032.67 USD) and a total intangible economic burden of 66,7481.5 RMB (97,799.49 USD). We estimate that injuries in elementary and secondary school 
Table 4 Average direct, indirect, intangible and total financial burden of student injuries per person-time (RMB) ( 1 RMB $=0.1465$ USD)

\begin{tabular}{|c|c|c|c|c|c|}
\hline & \multirow[t]{2}{*}{ Person-time } & \multicolumn{3}{|c|}{ Economic burden } & \multirow[t]{2}{*}{ Total } \\
\hline & & Direct & Indirect & $\overline{\text { Intangible }}$ & \\
\hline \multicolumn{6}{|l|}{ Sex } \\
\hline Boys & 216 & 751.6 & 239.7 & 1823.1 & 2814.4 \\
\hline Girls & 149 & 643.5 & 249.5 & 1836.8 & 2729.8 \\
\hline \multicolumn{6}{|l|}{ Grade } \\
\hline $1-3$ & 67 & 854.2 & 340.3 & 2480.6 & 3675.1 \\
\hline $4-6$ & 100 & 556.9 & 197.2 & 1443.8 & 2197.9 \\
\hline $7-9$ & 117 & 448.3 & 244.7 & 1020.6 & 1713.6 \\
\hline $10-12$ & 81 & 1146.3 & 219.8 & 2932.1 & 4298.1 \\
\hline \multicolumn{6}{|l|}{ Residence } \\
\hline Urban & 90 & 1056.5 & 486.7 & 2632.7 & 4175.9 \\
\hline Suburban & 138 & 593.1 & 162.7 & 1460.6 & 2216.3 \\
\hline Exurban & 137 & 593.3 & 165.7 & 1671.4 & 2430.4 \\
\hline \multicolumn{6}{|l|}{ Causes } \\
\hline Unintentional falls & 112 & 724.4 & 340.6 & 1520.9 & 2586.0 \\
\hline Collisions/Strikes & 68 & 326.3 & 294.4 & 1347.0 & 1967.7 \\
\hline Sprains & 63 & 311.4 & 83.0 & 592.5 & 986.9 \\
\hline Cuts/Sharp instrument & 37 & 93.6 & 66.2 & 152.4 & 312.3 \\
\hline Burns and scalds & 21 & 347.5 & 128.6 & 948.0 & 1424.1 \\
\hline Traffic accidents & 20 & 2300.9 & 525.0 & 6685.0 & 9510.9 \\
\hline Animal attacks & 14 & 210.9 & 39.3 & 357.9 & 608.0 \\
\hline Crush & 13 & 283.1 & 57.7 & 631.5 & 972.3 \\
\hline Medical complications & 8 & 7688.1 & 625.0 & 17506.3 & 25819.4 \\
\hline Explosion & 4 & 287.5 & 125.0 & 500.0 & 912.5 \\
\hline Poisonings & 3 & 2066.7 & 1033.3 & 16900.0 & 20000.0 \\
\hline Others & 2 & 1502.5 & 0.0 & 1500.0 & 3002.5 \\
\hline Total & 365 & 707.5 & 243.7 & 1828.7 & 2779.9 \\
\hline
\end{tabular}

students in Xiamen cause a direct economic burden of 27.42 million RMB (4.02 million USD), an indirect economic burden of 9.44 million RMB (1.38 million USD), an intangible economic burden of 70.87 million RMB (10.38 million USD), and a total economic burden of
108 million RMB (15.82 million USD) each year. We must take effective measures to control and reduce the occurrence of injuries because of the serious economic burden of student injuries on individuals, families, and society.

Table 5 Family Burden Scale of Diseases (FBS) dimension measurements

\begin{tabular}{|c|c|c|c|c|c|c|}
\hline \multirow[t]{2}{*}{ Dimension } & \multicolumn{2}{|c|}{ No impact } & \multicolumn{2}{|c|}{ Moderate impact } & \multicolumn{2}{|c|}{ Serious impact } \\
\hline & $n$ & Ratio (\%) & $n$ & Ratio (\%) & $n$ & Ratio (\%) \\
\hline Financial burden (FM1) & 125 & 41.3 & 46 & 15.2 & 132 & 43.6 \\
\hline Disruption of family routine activities (FM2) & 106 & 35.0 & 56 & 18.5 & 141 & 46.5 \\
\hline Disruption of family leisure (FM3) & 126 & 41.6 & 46 & 15.2 & 131 & 43.2 \\
\hline Disruption of family interaction (FM4) & 163 & 53.8 & 30 & 9.9 & 110 & 36.3 \\
\hline Effect on Physical health (FM5) & 215 & 71.0 & 0 & 0.0 & 88 & 29.0 \\
\hline Effect on Mental health (FM6) & 221 & 72.9 & 0 & 0.0 & 82 & 27.1 \\
\hline The entire scale (FM) & 76 & 25.1 & 109 & 36.0 & 118 & 38.9 \\
\hline
\end{tabular}


This study found that the intangible economic burden of injury accounted for nearly $70 \%$ of the total economic burden. Injuries not only wasted money for individuals, families, and society but also were a burden on the emotional wellbeing of individuals and families. Because elementary and secondary students are the hope of each family and of society in general, the psychological loss for families caused by injuries is substantial. Therefore, the overall costs saved for society by effective prevention and control measures to reduce the occurrence of injuries in elementary and secondary students will be far greater than the actual material goods and money saved on treatment.

Injuries cause both the burden of disease and severe psychological pressure and life consequences for members of the family. The impacts of injuries on elementary and secondary school students are pervasive and multidimensional. Injuries are undoubtedly preventable with appropriate prevention and control measures. According to our research results, we provide the following suggestions for the government, the local Centers for Disease Control and Prevention (CDC), schools and families to develop effective measures to control the incidence of injuries.

First, the government should focus and invest more on injury control and prevention within the school sector, especially in suburban and exurban areas. Secondly, schools should practice safety management strictly and do their best to eliminate the risk factors of injuries. Third, besides helping students to obtain academic achievements, schools should work together with parents on strengthening student physique, cultivating safety awareness, and improving self-protection abilities. For instance, Björklund et al. introduced a school-based intervention program, "Together at school", in Finland to promote elementary school students' socio-emotional skills and mental health [24]. Finally, the local CDC should collaborate with schools to establish a system for monitoring the incidence and prevalence of injuries to collect relevant information to provide theoretical and empirical support for the prevention programs [25]. Injury control and prevention among elementary and secondary school students is essential and will help in multiple ways to reduce the burden on the family to build a harmonious family and society.

Because of time and man-power limitations, our study collected fewer than 3,000 usable questionnaires and conducted analyses based on these data. Therefore, our results might not be representative of all the elementary and secondary school students in Xiamen, China. Although the randomly chosen schools appared to be representative and we do not believe that the sample size has biased our results, closer investigation about their representation needs to be done in the future. We were aware of this limitation, and we encourage scholars and practitioners to conduct more extensive surveys to obtain more representative results.

\section{Conclusion}

The injury incidence among elementary and secondary students in Xiamen is lower than Guangdong and Zhejiang but high er than Beijing and Shanghai. Injuries cause enormous economic and familial burdens and threaten students' health and life. Childhood and adolescent injuries have become a serious public health problem and require the urgent attention of the government, society, schools, and families.

\section{Competing interests}

The authors declare that they have no competing interests.

\section{Authors' contributions}

$Y F, X Z, H Y$, and LD conceived and designed the study. XZ, HY, and LD collected the data. YF, XZ, WC, and FL analyzed the data. YF, XZ, WC, FL, MY, and ZG prepared the manuscript. YF supervised the research. All authors read and approved the final manuscript.

\section{Acknowledgements}

We would like to thank all participating schools for their efforts, and to thank all participating students and their parents.

\section{Funding}

This study was supported by Xiamen Centers for Disease Control and Prevention Funding (grant number XDHT2008231A).

\section{Author details}

${ }^{1}$ Key Laboratory of Health Technology Assessment in Fujian Province University, School of Public Health, Xiamen University, Xiamen, China. ${ }^{2}$ State Key Laboratory of Molecular Vaccinology and Molecular Diagnostics, School of Public Health, Xiamen University, Xiamen, China. ${ }^{3}$ Department of Statistics, School of Economics, Xiamen University, Xiamen, China. ${ }^{4}$ Xiamen Institute for Healthcare of Middle and Primary Schools, Xiamen, China. ${ }^{5}$ Division of Health Education, Xiamen Center for Disease Control, Xiamen, China.

Received: 18 November 2014 Accepted: 31 March 2015 Published online: 10 April 2015

\section{References}

1. Sminkey L. World report on child injury prevention. Inj Prev. 2008;14(1):69.

2. World Health Organization. Violence, Injuries, and Disability: Biennial 2006-2007 Report. Geneva, Switzerland: World Health Organization; 2008.

3. Krug EG, Sharma GK, Lozano R. The global burden of injuries. Am J Public Health. 2000;90(4):523-6.

4. Danseco ER, Miller TR, Spicer RS. Incidence and costs of 1987-1994 childhood injuries: demographic breakdowns. Pediatrics. 2000;105(2):E27.

5. Centers for Disease Control and Prevention, National Center for Injury Prevention and Control. National Action Plan for Child Injury Prevention. Atlanta (GA): CDC, NCIPC; 2012.

6. Ji C, Tao F. The prevention of unintentional injury among children and adolescents. Chin J Public Health. 2005;21(9):1150-2.

7. Zhou Y, Baker TD, Rao K, Li G. Productivity losses from injury in China. Inj Prev. 2003;9(2):124-7.

8. Bener A, Hyder AA, Schenk E. Trends in childhood injury mortality in a developing country: United Arab Emirates. Accid Emerg Nurs. 2007;15(4):228-33.

9. Polinder S, Haagsma JA, Toet H, Brugmans MJ, van Beeck EF, Eurocost, groups Ar. Burden of injury in childhood and adolescence in 8 European countries. BMC Public Health. 2010;10:45.

10. Centers for Disease Control and Prevention. Vital signs: unintentional injury deaths among persons aged 0-19 years — United States, 2000-2009. MMWR. 2012;61(15):270-6. 
11. Harvey A, Towner E, Peden M, Soori H, Bartolomeos K. Injury prevention and the attainment of child and adolescent health. Bull World Health Organ. 2009;87(5):390-4

12. Rossler R, Donath L, Verhagen E, Junge A, Schweizer T, Faude O. Exercisebased injury prevention in child and adolescent sport: a systematic review and meta-analysis. Sports Med. 2014;44(12):1733-48.

13. Zhou C, Lu G, Wu A, Zhou Y, Wu A. A preliminary evaluation of interventions for injuries in primary and middle school students. Chin J School Health. 2001;22(1):30-1.

14. Wang S. The content and method of injury epidemiology study. Lit Inform Prev Med. 1998:4(3):299-300.

15. Du Y, Chen H, Jia G, Liu X. Analysis of the family burden of injured patients and the influencing factors. J Huazhong Univ Sci Tech [Health Sci] 2003;32(6):662-4

16. Yu M, Zhong J, Li J. Study on the risk factors of injuries among school students in Zhejiang province. Chin J Epidemiol. 2007;7:589-92.

17. Peng C, Zhou L, Dong G. Study on incidences and risk factors of injuries among adolescents in Shenzhen. Chin J Soc Med. 2009;26(3):168-71.

18. Pan W, Yuan B. Incidences and risk factors of injuries among adolescent in Jiangsu province. Chin J Sch Health. 2010;31(3):323-5.

19. Ma W, Xu Y, Cong L. Epidemiological characteristics of injuries among primary and secondary school students in Guangdong. Chin J Sch Health. 2006;27(1):47-9.

20. Liu W, Zhang W, Mai J. Influencing factors of injury among primary and secondary school students in Guangzhou. Chin J Public Health. 2010;26 (3):311-2.

21. Cao R, Er Y, Zhang J. Epidemiological analysis of student injury in Haidian and Pinggu Districts of Beijing City. Chin J Health Educ. 2008;24(11):822-4.

22. Zhou Y, Luo C, Lu X. Epidemiological survey of injuries among primary and secondary school students in Shanghai. Chin J Sch Health. 2010;31(11):1369-72.

23. Bureau XS. The national bureau of statistics Xiamen team. In: 2010 Xiamen special economic zone yearbook. Beijing: China Statistics Press; 2013.

24. Björklund K, Liski A, Samposalo H, Lindblom J, Hella J, Huhtinen $H$, et al. "Together at school" - a school-based intervention program to promote socio-emotional skills and mental health in children: study protocol for cluster randomized controlled trial. BMC Public Health. 2014;14:1042.

25. Fleiter J, Senserrick T. Social policy implications relating to road trauma in a rapidly motorizing world: the example of China. Asian Soc Work Policy Rev. 2015:9(1):70-8

\section{Submit your next manuscript to BioMed Central and take full advantage of:}

- Convenient online submission

- Thorough peer review

- No space constraints or color figure charges

- Immediate publication on acceptance

- Inclusion in PubMed, CAS, Scopus and Google Scholar

- Research which is freely available for redistribution 